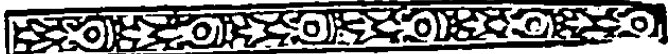

\section{EL LAMENTO DE PLEBERIO: CONTRASTE Y PARECIDO CON DOS LAMENTOS EN CARCEL DE AMOR}

\author{
Luis Miguel Vicente \\ University of California, Los Angeles
}

De todos los personajes de Celestina, Pleberio ha sido seguramente el que ha suscitado posturas más encontradas entre los estudiosos. Eso se debe, en parte, a su posición estratégica en la obra, como broche final de la tragedia y momento de reflexión panorámica sobre los desastrosos acontecimientos que se han sucedido. Henry Mendeloff en su articulo "Pleberio in Contemporary Celestina Criticism" (Romance Notes 13,[197172]: 369-73), reseña algunas de las más diversas opiniones que los estudiosos han mantenido respecto al significado del monólogo de Pleberio. Para este critico, las posturas pueden resumirse en dos bandos, el de los literalistas y el de los trascendentalistas. Para los primeros, el lamento de Pleberio es enteramente personal, como corresponde al personaje del padre, y no tiene implicaciones moralistas universales. Trabajos de sobra reconocidos como el de Bataillon, La Célestine selon Fernando de Rojas (Paris, 1961) o el Otis H. Green, "Did the 'World' Create Pleberio?" (Romanische Forschungen 77 [1965]: 108-10), entre otros, sostienen la tesis literalista. Para los transcendentalistas, en cambio, el lamento de Pleberio es una suerte de portador del propósito moral de la obra, de su moraleja. En este grupo se inscribirian, por ejemplo, el trabajo de Stephen Gilman, "Fernando de Rojas as Author" (Romanische Forschungen 76 [1964]: 225-90); o el articulo de Wardropper, "Pleberio's Lament for Melibea and the Medieval Elegiac Tradition" (Modern Language Notes 79 [1964]: 140-52). Entre esos dos polos podemos situar el monumental trabajo de Maria Rosa Lida de Malkiel, La originalidad artistica de "La Celestina" (Buenos Aires, 1962), que sirve de puente entre ambas posturas en tanto reconoce que Pleberio se hace portador de la moraleja al tiempo que no pierde su individualidad como personaje.

Para una justa valoración de la función y originalidad del llanto de Pleberio en Celestina, conviene revisar la tradición de este tipo de lamentos en otras obras medievales o de la herencia clásica. ${ }^{1}$ Mi propósito en estas páginas es cotejar el monólogo de Pleberio con "el llanto de su madre de Leriano" y con las palabras, lamento también, que dirige la reina madre a Laureola, ambos en Cárcel de Amor. Aunque la influencia 


\section{CELESTINESCA}

de la novela sentimental en Celestina ha sido magistralmente ponderada por Maria Rosa Lida, no se ha hecho, que sepamos, una comparación exhaustiva entre los lamentos mencionados de una y otra obra. Al cotejarlos, se ratifica la influencia de la obra de Diego de San Pedro en la de Rojas, pero también se pone de relieve el distanciamiento literario e ideológico de una y otra. Empecemos por referir los tres lamentos a la tradición del escrito funeral, para ver hasta qué punto se ajustan a un modelo ideal, y dónde empieza la originalidad.

Para Eduardo Camacho, la estructura elegiaca ideal consta de cuatro partes, a saber: 1) Presentación del acontecimiento, anuncio de la muerte; 2) Lamentación. Llanto. Invitación, magnificación del llanto, etc.; 3) Panegirico; 4) Consolación directa. ${ }^{2}$ Por su parte, Maria Rosa Lida escribe que "la convención retórica exigia tres partes al poema fúnebre: consideraciones sobre la muerte, lamento de los sobrevivientes y alabanzas del difunto." ${ }^{3}$ Con el orden cambiado, esos elementos aparecen en los dos discursos de Cárcel de Amor; en el de Pleberio, en cambio, faltan los elogios de la difunta, en cuanto a su valor en sí misma, aunque se magnifica su valor como heredera. ${ }^{4}$ Los elogios, normalmente lugares comunes, que aparecen en boca de la madre de Leriano o en la de Laureola, no pueden decirse de Melibea. La reina madre alaba sobre todo la inocencia y bondad de Laureola.

Por el contrario, Melibea ha perdido esas virtudes: la inocencia al entregarse a Calisto y la bondad, como Pleberio le reprocha, por suicidarse sin haber tenido lástima de sus padres, "¿Por qué te mostraste tan cruel con tu viejo padre?" (p. 236). La otra diferencia, desde la perspectiva de los padres, es que no hay asomo de consolación para Pleberio, mientras que las madres de Laureola y Leriano encuentran consuelo en la trascendencia de la vida eterna: la reina porque colige que la sentencia de muerte que pesa sobre Laureola se explica por la voluntad de Dios que ha elegido a su hija como mártir, "Pon, hija mia, el coraçón en el cielo; no te duela dexar lo que acaba por lo que permanece; quiere el Señor que padezcas como mártir porque gozes como bienaventurada" ( $p$. 136); la Duquesa Coleria, madre de Leriano, porque entiende que la muerte, a fin de cuentas, ha de reunirla pronto con su hijo, "no eres mala del todo [Muerte], porque si con tus obras causas los dolores, con ellas mismas los consuelas levando a quien dexas con quien levas" (p. 174). Además, su hijo ha muerto querido de todos sus amigos, y virtuoso; es decir, ha servido a su dama fielmente y sin manchar ni su propia fama ni la de Laureola.

Leriano ha muerto en casto servicio de su dama; ha llevado su propia corona de espinas, y al fin, ha acabado la vida comulgando con las dos cartas de la amada, para no perjudicar su fama. Es merecedor, por tanto, de todos los elogios: "Tú temeroso de Dios; tú amador de la virtud; tú enemigo del vicio; tú amigo de amigos; ${ }^{5}$ tú amado de los tuyos!" ( $p$. 


\section{CELESTINESCA}

173). Es decir, Leriano muere canónicamente dentro de la tradición marcada por el Ars Moriendi, "which provides the context for Leriano's death," en palabras de Michael Gerli. ${ }^{6}$ Mientras Leriano es enemigo del vicio, los amantes de Celestina no viven para otra cosa. Esa es una de las diferencias fundamentales: dentro de los amadores los hay virtuosos como Leriano y lascivos como Calisto.

Por lo demás, sí sigue el discurso de Pleberio los modelos ideales de elegia: hay primero unas consideraciones quejumbrosas en torno a la muerte, exactamente igual que en el discurso de la madre de Leriano, aunque en distinto orden: ambos, sexagenarios, increpan a la muerte que haya alterado el orden natural previsible llevándose a sendos hijos de veinte años: " $\mathrm{O}$ muerte [...] sin ley y sin orden te riges. Más razón havia para que conservases los veinte años del hijo moço que para que dexases los sesenta de la vieja madre,"7 exclama la madre de Leriano; y parecido se expresa Pleberio, "Más dignos eran mis sesenta años de la sepultura, que tus veinte" (p. 232).

Parece, pues, que de la composición elegiaca, el lamento de P.leberio sólo ha conservado parte de la estructura, en tanto que ha suprimido dos aspectos esenciales de la elegia como son los elogios del difunto y la consolación, lo cual pondera efectivamente el pesimismo de la obra y, por supuesto, su originalidad. El por qué de la ausencia de esos dos elementos en el discurso de Pleberio y no asi en los lamentos de la reina y la duquesa de Cárcel de Amor, ${ }^{8}$ queda en parte explicado arriba, cuando se habla del tipo de consuelo que reciben las dos madres frente al que no puede recibir Pleberio. Pero la razón de esa diferencia se perfila aún más clara si analizamos lo que los padres dicen que ha sido la causa del morir de sus hijos. La madre de Laureola, convencida de la inocencia de su hija, no halla causa razonable por la que Laureola deba morir, y se consuela, como se ha señalado, pensando que Dios la haya elegido entre sus mártires. Si por algún pecado le viene tan injusta muerte, no ha sido de su hija, sino suyo propio, "No hallo por cierto otra causa sino que puede más la muchedumbre de mis pecados que el merecimiento de tu justedad, y quiso [Dios] que mis errores comprehendiesen tu inocencia" ( $p$. 136). Claro que, precisamente por su inocencia, Laureola no va a morir, para que no tome un sentido siniestro la pregunta de su madre, "¿por qué consiente Dios que mueras?" (p. 136). Lo que interesa aqui es destacar cómo la madre ha sugerido que pueden haber sido sus propios pecados los causantes de la muerte de la hija. La misma idea la vamos a encontrar en Pleberio: "¡Oh amor, amor, [...] Herida fue de ti mi juventud, [...] ¿Cómo me soltaste, para me dar la paga de la huida en la vejez? [...] No pensé que tomabas en los hijos la venganza de los padres" (p. 235). Sin embargo, sobre un sentimiento de culpa semejante, Laureola es inocente y Melibea no, razón en parte por la que la reina halla el consuelo que le falta a Pleberio. 
Por su parte, la madre de Leriano parece ignorar la causa por la que su hijo está dejándose morir, " $\mathrm{O}$ lumbre de mi vista, o ceguedad della misma, que te veo morir y no veo la razón de tu muerte!" (p. 173); para su madre, es culpa de la fortuna (también para Pleberio y la madre de Laureola) pues su hijo, contra lo razonable, muere "sin tiempo y sin dolençia." Sin embargo, algo parece saber de la clase de dolencia que su hijo tiene, porque exclama: "Bienaventurados los baxos de condición y rudos de engenio, que no pueden sentir las cosas sino en el grado que las entienden; y malaventurados los que con sotil juizio las trascenden, los cuales con el entendimiento agudo tienen el sentimiento delgado; pluguiera a Dios que fueras tu de los torpes en el sentir" (p. 173). Es decir, que su hijo muere por conocer y sentir algo trascendente, por tener una nobleza de espiritu especial; y ella, si llora como madre su pérdida, de otro lado admira su alta condición.

Frente a esos dos lamentos femeninos, que en el elogio de los llorados hallan parte de consuelo, Pleberio of rece un lamento verdaderamente desesperado. En relación con el dicho "Bienaventurados los baxos de engenio" de la madre de Leriano, Pleberio proclama bienaventurados a los que dejan el mundo: "Muchos te dejaron [mundo] con temor de tu arrebatado dejar; bienaventurados se llamarán cuando vean el galardón que a este triste viejo has dado en pago de tan largo servicio" (p. 253); y en los mismos términos se dirige al amor más adelante: "Bienaventurados los que no conociste o de los que no te curaste" (p. 253). Explícitamente, frente a esos bienaventurados que dejaron el servicio del mundo, Pleberio reconoce haber dedicado su vida al servicio del mundo de una parte, ${ }^{9}$ y de otra también una época de su vida al servicio del amor. Lo más significativo, en cualquier caso, es que la alusión al mundo se da exclusivamente en el llanto de Pleberio, y no en los otros dos, donde sí aparecen en cambio las imprecaciones a la muerte, a la fortuna y al amor (el amor está ausente en el discurso de la reina madre en Cárcel de Amor porque no ha sido el amor lo que ha movido a Laureola sino la piedad). Parece que la noción "servicio del mundo" no cabia en el estado nobiliario-caballeresco como opuesto al servicio de Dios, del mismo modo que no se oponen ambos conceptos en Don Juan Manuel.

Pero Pleberio representa ya otra realidad distinta, es un rico mercader que se ha dedicado a aumentar su hacienda como un valor en si misma, y eso ya si entra en franca oposición con la doctrina de la Iglesia según la formulaban los Santos Padres (amor a los bienes materiales $o$ cupiditas, versus amor a Dios o caritas). En una obra en la que hemos visto destruir a los personajes movidos por la cupiditas, en su faceta sexual o material, creemos que Pleberio no es una excepción. Su dolor final es, tal vez, el pago a su codicia de bienes (servicio del mundo). Al final, Pleberio ha envidiado a esos bienaventurados que dejaron las cosas 


\section{CELESTINESCA}

del mundo. El mundo se coloca significativamente a la cabeza de todos los elementos increpados en su llanto. La muerte y la fortuna (no está en su mano cambiarlas) vienen inextricablemente de arriba. Pero en cuanto al amor y al mundo, las dos caras de la cupiditas, son responsabilidad propia y está en el libre albedrio de cada hombre, según la doctrina cristiana, el rechazarlos o el seguirlos. De esos dos males el que más le incumbe a Pleberio es el mundo, porque el amor lo dejó atrás.con los años jóvenes, en tanto que confiesa haber dedicado un "largo servicio" al mundo.

Al mundo pues subordina Pleberio todos los demás males porque los incluye a todos: "Del mundo me quejo, porque en si me crió, porque no me dando vida no engendrara en él a Melibea; no nacida no amara; no amando, cesara mi quejosa y desconsolada postrimería" (p. 236). Podría aducirsenos, en base a una lectura absolutamente pesimista existencialista del monólogo, que 'mundo' para Pleberio equivale a la vida misma. Aparte del anacronismo que supone tal vison "existencialista," ¿cómo se explicaria, en ese caso, la alusión citada de Pleberio a los bienaventurados que abandonan el servico del mundo? Puesto que Pleberio contempla, a pesar de su dolor de padre, la posibilidad de no servir al mundo, hemos de tener en cuenta esa posibilidad, que retomaremos más tarde, a la hora de meditar sobre la moralidad implícita de su monólogo. A la misma moralidad implicita apuntan las exclamaciones de Pleberio sobre la causa de la muerte de su hija, que adquiere una dimensión más trascendente que la de la muerte misma, "yo no lloro triste a ella muerta, pero la causa desastrada de su morir" (p. 234).

La causa de su morir ha sido su amor por Calisto que, como amor concupiscente, ha desencadenado una muerte desastrosa y súbita lejos del ritual refinado de Leriano, verdadero ejemplo de Ars Moriendi. Contra ese tipo de amor-cupiditas increpa Pleberio duramente, "le leña que gasta tu llama [amor] son almas y vidas de humanas criaturas, las cuales son tantas, que de quien comenzar pueda, apenas me ocurre" (p. 236). En lo que al amor respecta vemos en las palabras de Pleberio una carga moral negativa que no veiamos en los lamentos de Cárcel de Amor, y que nos van aclarando por qué en el monologo de Pleberio no hay consolación. Se presenta a Melibea como una suicida por amor carnal en fragante oposición a la bienaventurada Laureola que, a punto de morir mártir 0 viviendo casta, vence la tentación del amor humano; en contraste también con Laureano que, si se deja morir, lo hace en servicio de la fama de Laureola, acabando sin macular la castidad de la amada, y por lo tanto, heroicamente.

En Cárcel de Amor no hay antagonismo entre Dios y el mundo; sencillamente no hay mundo. El amor en la obra aparece desligado de la esfera semántica de mundo $y$ vinculado más bien a un universo caballeresco ideal, en virtud del cual el servicio a la dama elimina la 


\section{CELESTINESCA}

posibilidad del galardón erótico, y por ende, significa la superación casi sobrehumana de la tentación de la carne. A veces, esta superación del pecado exige incluso la muerte del amante como en el caso de Leriano, o el sufrimiento de Laureola, que por conservar su virtud (honor), debe superar la piedad que siente por su enamorado. El esfuerzo de ambos no queda sin premio. Laureola es ensalzada hasta su cumbre de princesa heredera, mientras que Leriano, sutil como su madre le describe, traspasa la barrera de la vida sólo por el peso mortal de su sentimiento contra el que, como su madre también ha ponderado, ni su mucha virtud, ni su juventud, ni su ser tan querido de todos, pueden hacer nada.

La condenación de su alma en esta obra ni se sugiere siquiera; se nos dice, en cambio, que "sus honras fueron conforme a su merecimiento" (p. 176), aludiendo, como nos aclara Whinnom (ed. de Cárcel de amor, p. 176), a la misa solemne que se hace por los difuntos dias después del entierro; lo cual nos da a entender que, cuando menos, Leriano no es considerado un suicida como Melibea, y que la causa de su muerte, a juicio del autor, no entra en conflicto con la salvación de su alma, antes bien, como Michael Gerli señalaba, lo eleva espiritualmente. No en vano algunos estudiosos han equiparado con pruebas evidentes la muerte de Leriano con la Pasión de Cristo ${ }^{10}$ o con otros pasajes biblicos; ${ }^{11}$ de modo que si en Laureola veia su madre una mártir de Dios, no menos ocurre con Laureano a quien su madre describe como un espiritu sutil muerto por una causa trascendente, que no afecta a "los baxos de condiçión y rudos de engenio," sino a aquellos capaces de soportar una pasión que recuerda de cerca la del mismo Jesucristo.

Frente a la ausencia de mundo en Cárcel de amor. Celestina no es otra cosa que la plasmación del mundo con toda su compleja maraña de relaciones humanas egoistas movidas por la cupiditas denostada por los Santos Padres, ora en su faceta libidinosa, ora como codicia de dinero o bienes temporales: los amantes encarnando la cara lasciva de la cupiditas; Celestina, sus pupilas, y los criados de Calisto con ambos tipos de codicia sexual y material; y los padres de Melibea, en el otro extremo, preocupados en su prosperidad material (codicia de bienes temporales). Son todos servidores del mundo. Un mundo en el que, por ser mundo de pecado, no cabe Dios hasta el momento del castigo implacable: "Corremos por los prados de tus viciosos vicios [mundo], muy descuidados, a rienda suelta; descúbresnos la celada, cuando ya no hay lugar de volver" (Pleberio, p. 233).

Para algunos como Wardropper, en su citado articulo (140-152), el discurso de Pleberio se emparenta con la elegia porque ésta permite frente al planctus la expresión de la angustia existencial más que religiosa. Sin embargo, hay que matizar que el tipo de angustia existencial de Pleberio se expresa a base de unos conceptos estrechamente ligados a la doctrina religiosa cristiana. En otras palabras, esa angustia de Pleberio, conlleva 


\section{CELESTINESCA}

un tipo de moralidad cristiana que se perfila aún mejor en el contraste con los dos monólogos de Cárcel de amor que hemos estudiado: en estos, el dolor elegiaco se vuelca básicamente contra dos elementos sobrehumanos, la muerte y la fortuna; las increpaciones de Pleberio, en cambio, se concentran sobre dos elementos humanos, el servicio del mundo y del amor, frente a los cuales el hombre ejerce la responsabilidad de su libre albedrio. Esos dos temas son, no por casualidad, los dos pecados más denostados por los Santos Padres (en realidad un solo pecado, cupiditas, con dos facetas). Si la diferencia entre los elementos increpados en los monólogos de ambas obras coincide tan nitidamente con lo que los Santos Padres han llamado cupiditas, creemos que debe dársele un relieve algo más que existencial al monólogo de Pleberio.

Es cierto que la funcion explicita de Pleberio en el monólogo es la de ser padre de la suicidada Melibea, y como padre, es cierto también que le corresponde expresar la angustia que le ocasiona el suicidio de su hija más que la moraleja. Sin embargo, la función implicita de su monólogo es moralizante en la medida en que su reconocimiento de las causas de la tragedia coincide exactamente con el concepto de pecado que sostiene la Iglesia. Si Pleberio ha puesto el mundo en el origen de todos los males, no ha sido por angustia existencial sino para redondear orgánicamente lo que Rojas mismo, con trasparente y radical ortodoxia, declara en los versos acrósticos: "Estando en el mundo yacéis sepultados" (p. 39).

Por tanto, no se trata de una moraleja individualizada y desconectada del resto de la obra, sino más bien, podemos decir con Parker que, "Pleberio's diatribe on love and the world is fully justified by events in the play (...). It is a genuine summing up." ${ }^{12}$ De ahi la originalidad de la elegia de Pleberio, de ahi que falten en ella el elogio del difunto y la consolación del que se lamenta, porque a Pleberio no le cabe invocar la justicia de Dios como hacía la madre de Laureola conociendo la inocencia de su hija, sino que aquél se reconoce a si mismo como servidor del mundo, a su hija como servidora del amor y, castigados con justicia, no le queda sino increpar a los pecados mismos, al mundo y al amor; y a los elementos que, como la muerte y la fortuna, han parado la vida en el momento más trágico, cuando "ya no hay lugar de volver," ni más consuelo que el quedar "in hac lachymarum valle" de claras connotaciones religiosas. ${ }^{13}$

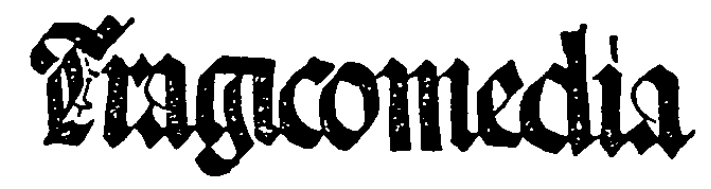




\section{CELESTINESCA}

\section{NOTAS}

${ }^{1}$ Para la Sra. de Malkiel, que estudia profusamente las fuentes de Celestina, Pleberio es una creación original y "Rojas no pudo encontrar en la comedia romana ni siquiera el germen remoto de su Pleberio" (p. 477); para ella, "el largo lamento de Pleberio, por su técnica--diálogo de hipertrofiado parlamento--y por su inspiración--ascetismo doctrinal de Petrarca--no procede del teatro romano" (p. 127). Antes bien, "no en el teatro romano, sino en la comedia elegiaca y en la novela sentimental del Renacimiento heredera de una larga tradición clásica y medieval, se adiestraron los autores de La Celestina en la pintura de conflictos animicos" (p. 132).

${ }^{2}$ Eduardo Camacho Guisado. La elegia funeral en la poesia española. Madrid: Gredos, 1969, pp. 21-24.

${ }^{3}$ Citada por Camacho, p. 16, de una de las notas de Maria Rosa Lida a su selección de Libro de buen amor, del Arcipreste de Hita, Buenos Aires: Losada, 1941, p. 159.

${ }^{4}$ Es de notar que la calidad de heredera de Melibea, por la que Pleberio se precia de haber perdido más que ninguno de los padres de la antiguedad clásica, aparece ya, enfatizada por su madre en Laureola; "podrá un cuchillo acaballa [tu vida], el cual dexará el padre culpado y la madre con dolor y la hija sin salud y el reino sin heredera" (p. 136).

${ }^{5}$ Pleberio invierte esos elogios de la madre de Leriano cuando increpa al amor: "Enemigo de amigos, amigo de enemigos" (p. 236).

${ }^{6}$ Michael E. Gerli. "Leriano's Libation: Notes on the Cancionero Lyric, Ars Moriendi, and the Probable Debt to Boccaccio." MLN 96 (1981): 416.

${ }^{7}$ Diego de San Pedro, Obras Completas, II. Cärcel de Amor. $2^{\mathrm{a}}$ ed., edición y notas de Keith Whinnom, Madrid: Castalia, 1983, pp. 17374. Se cita el texto de acuerdo a esta edición.

${ }^{8}$ Esquematizada la progresión de esos tres lamentos puede representarse del siguiente modo:

I. Lamento de Pleberio: 1) Quejas: no quiere vivir más. 2) Quejas contra la muerte, sin orden ntaural. 3) Valor de Melibea como heredera. Sin sentido el trabajo de su vida. 4) Quejas contra la fortuna. 5) Quejas contra el mundo tras confesar haberlo servido. Mejor haberlo dejado. 6) Quejas contra la causa del morir de Melibea: el amor. No es verdadero amor. 7) Vuelve a quejarse del mundo, motor de todos los demás males. 8) Quejas por la propia soledad. 


\section{CELESTINESCA}

II. Lamento de la madre de Leriano: 1) Quejas; no quiere vivir más. 2) Elogios del hijo. 3) Quejas contra la muerte, sin orden natural. 4) Quejas contra la furtuna. 5) Quejas contra la causa del morir de Leriano: el amor. El amor sólo se da en espíritus sutiles. 6) Quejas contra la muerte y consuelo en la misma muerte. 7) Elogios de la virtud de Leriano. 8) Quejas por la propia soledad.

III. Lamento de la madre de Laureola: 1) Elogios de su hija. 2) Quejas por la injusta sentencia de muerte. 3) Quejas contra su ventura. 4) Quejas contra la muerte sin orden natural. 5) Vuelve a los elogios de su hija. 6) Quejas contra la causa de la condena de Laureola: el falso testimonio de Persio. 7) Consolación: Dios elige a su hija de mártir. 8) Despedida de su hija sin querer vivir más.

${ }^{9}$ El servicio del mundo, además, está implícito en las tan citadas imprecaciones de Pleberio, "¿para quièn edifiqué torres; para quién adquiri honras; para quién planté árboles; para quién fabriqué navios?" ( $p$. 232).

${ }^{10} \mathrm{De}$ ese aspecto dan cuenta, entre otros, los trabajos de Wardropper, "El mundo sentimental de Cárcel de Amor," Revista de Filologia Española 37 (1953): 168-193; también el trabajo de Deyermond, A Literary History of Spain. The Middle Ages. New York: Barnes and Noble, 1971, pp. 164-65.

11 Joseph F. Charpenning en su articulo "Leriano's Consumption of Laureola's letters in the Carcel de amor." Modern Languages Notes 95 (1980): 442-45, añade al mas que posible recuerdo de la Pasión de Cristo, otros pasajes biblicos para él más obvios y explicitos, "namely, the prescription for the drinking of water into which the words of a curse have been washed in cases of suspected adultery in Numbers 5.11-31, and the eating of scrolls by the prophet Ezekiel in Ezekiel 2.9-3.31 [etc.]."

${ }^{12}$ Charles F. Fraker, "The Importance of Pleberio's Soliloquy," Romanische Forschungen 78 (1966), p. 529.

13 Debo agradecer la ayuda del profesor Joaquín Gimeno Casalduero, con cuyos comentarios y magisterio volví a enfrentarme a la lectura del monólogo de Pleberio.

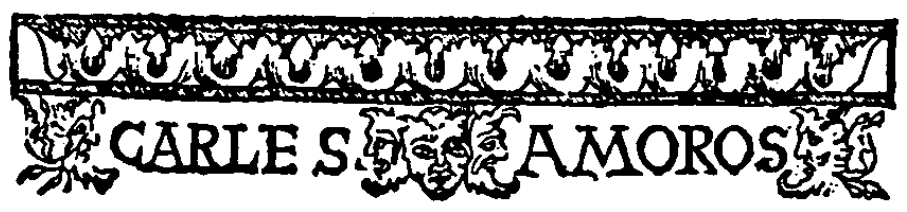




\section{CELESTINESCA}

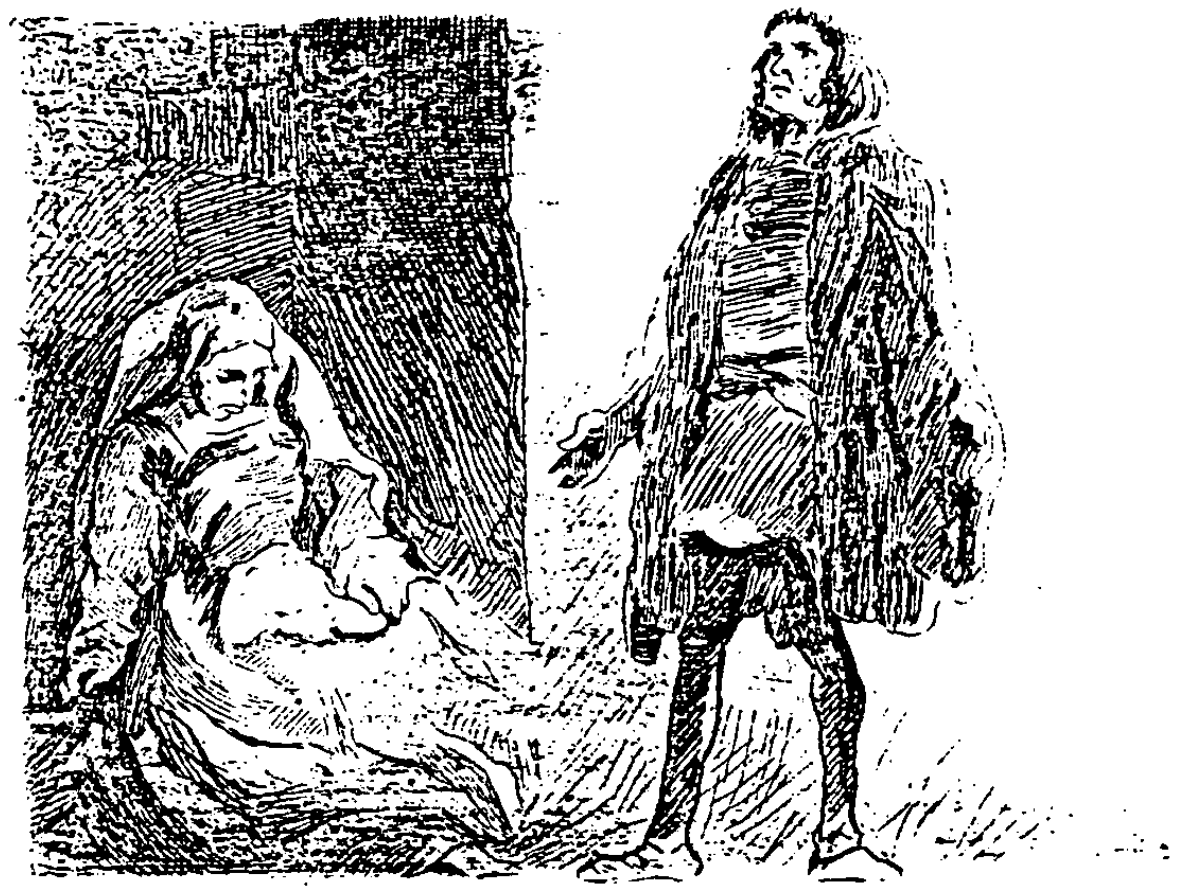

Acto XXI. Edición de la TCM. Valencia, 1948. Ilustracion de J. Segrelles. 